\title{
Stable isotopes and body composition in children: History, fundamentals, and clinical applications
}

\author{
Wendell Costa Bila ${ }^{1^{*}}$, Joel Alves Lamounier ${ }^{1}$, André Everton de Freitas $^{2}$, \\ Valmin Ramos Silva ${ }^{3}$, Sylvia Dias Turani ${ }^{4}$, José Eduardo Dutra de Oliveira ${ }^{5}$ \\ ${ }^{1}$ Graduate Program in Health Sciences, Federal University of São João Del Rei-West Campus Center, Divinópolis, Brazil; \\ ${ }^{*}$ Corresponding Author: wendellbila1@gmail.com \\ ${ }^{2}$ Graduate Program in Child and Teenager Health-Medicine School-UFMG Belo Horizonte, College of Health and Human \\ Ecology-FASEH Vespasiano, Brazil \\ ${ }^{3}$ Faculty of Medicine, School of Sciences of Santa Casa de Misericordia of Vitoria, Nossa Senhora da Glória Children's \\ Hospital, Vitória, Brazil \\ ${ }^{4}$ Faculty of Medicine, Federal University of São João Del Rei-West Campus Center, Divinópolis, Brazil \\ ${ }^{5}$ Faculty of Medicine, University of São Paulo-Ribeirão Preto, Brazil
}

Received 20 May 2013; revised 30 June 2013; accepted 15 July 2013

Copyright (C) 2013 Wendell Costa Bila et al. This is an open access article distributed under the Creative Commons Attribution License, which permits unrestricted use, distribution, and reproduction in any medium, provided the original work is properly cited.

\section{ABSTRACT}

The aim of this study was to gather information on the use of stable isotopes to measure total body water and body composition scan in children. We selected studies in the last 13 years; in addition to classical studies on the subject, indexed in the database PubMed, LILACS, BVS and SciELO. The body composition was characterized by the amount of bone tissue, muscle and adipose tissue, also including the organs as well as levels of body water. Your knowledge becomes increasingly important in light of the changes that occur in the nutritional status of various types of diseases in frameworks, such as diabetes mellitus, protein energy malnutrition, in cases of obesity and metabolic syndrome. The ability to accurately assess body fat mass especially in children is associated with the importance of effective strategies for prevention and treatment of childhood obesity. Historically, in addition to clinical applications, measurements of total body water were used to determine body composition in nutritional studies. To the knowledge of the body composition, the body water can be measured and used by the ingestion of a dose of labeled water. The measured isotope enrichment is a function of the amount of body water. The method of deuterium is particularly interesting for the assessment of body composition in children, due to its characteristics of collection and analysis.
Keywords: Body Water; Deuterium; Body Composition; Doubly Labeled Water; Obesity; Children

\section{INTRODUCTION}

The body composition is characterized by the amount of bone tissue, muscle and adipose tissue, also including the organs as well as levels of body water. Your knowledge becomes increasingly important in light of the changes that occur in the nutritional status of various types of diseases and frameworks, such as diabetes mellitus, protein energy malnutrition, in cases of obesity and metabolic syndrome, which seems to be a genuine phenomenon in children, uncommon in non-obese, but highly prevalent among obese children [1].

Increasingly studies related to knowledge of the worldwide phenomenon of childhood obesity are found, such as those conducted by Larsen, et al. (2012) in Danmark [2], Gardner, et al. (2011) in Caribbean [3], Bishwalata (2010) in India [4], Fuiano, et al. (2008) in Italy [5], Amin, et al. (2008) in Saudi Arabia [6], Otero-Gonzáles and García-Fragoso (2008) in Puerto Rico [7], Padula and Salceda (2008) in Argentina [8], Khang and Park (2011) in South Korea [9], Lazarou, et al. (2007) in Cyprus [10] and Abrantes, et al. (2003) in Brazil [11].

The measurement of body composition in children and adolescents is, thus, becoming increasingly common. The normal values for these measures and their relationship with health risk have clinical implications [12]. The current obesity epidemic influences various decisions, with particular focus on body fat percentage $(\% \mathrm{BF})$, with 
urgent establishment of their definitions, rather than relying solely indices involving weight and height. The ability to accurately assess the actual body fat mass (FM) in children is associated with the importance of effective strategies for prevention and treatment of childhood obesity [13].

In vivo techniques do not measure body composition directly, but to predict from measurements of body properties [14]. Thus, the total body water (TBW) can be used and measured by the ingestion of a dose of labeled water [15].

The ideal substance for the determination of the TBW should be a "marker" water which is diffused in all compartments of the body fluid within a short period of time, achieving a uniform and stable equilibrium concentration which can be measured $[16,17]$. The theoretically ideal marker is the isotope of hydrogen or oxygen, and justifications for the use of deuterium are often presented [17].

The isotopic dilution is particularly useful in children and infants, due to the simplicity of application of the technique and the fact that it could be easily used in field studies. Some disease states may show changes in body hydration and also interfere with the hydration of fat free mass (FFM). These cases should be treated with caution, because they prevent the use of the method as a useful clinical tool $[14,18]$.

\section{METHODS}

The subjects were selected scientific articles published in the period between the years 2000 to 2013 indexed in Pubmed database, LILACS, BVS and SciELO, which explored the use of TBW to the knowledge of body composition, especially in children. Furthermore, it was decided to also consider classical studies on the subject, published by the scientific relevance, before the search period.

The main indexing terms used for the search were: body water, deuterium, body composition, doubly labeled water, obesity, children.

This article contains the following sections: "Measurement of body composition", "TBW and stable isotopes"; "TBW and deuterium"; "TBW and $\mathrm{H}_{2}{ }^{18} \mathrm{O}$ "; "Stable isotopes-Preparation and collection"; "Stable isotopes and laboratory analyzes", "Results and discussion", and "Conclusions".

\subsection{Measurement of Body Composition}

Models of two-component (2C) are ideal where the intention is to quantify fat and FFM, with greater precision than allowed by simpler methods [14]. Another known model for assessing body composition is the threecomponents (3C) which divides the body into fat, water and remaining dry FFM, which is assumed to have a constant between protein and minerals [19]. The refer- ence method for body composition is the 4-compartment model (4C), which combines the TBW measurements, body density and total body bone mineral density. This is necessary to estimate a fourth component - the $\% \mathrm{BF}$, and know the FM and FFM [12].

The model of body composition $4 \mathrm{C}$ is more robust to the inter-individual variability in the composition of the FFM, dividing body weight in fat, water, minerals, and protein [20]. However, the criterion $4 \mathrm{C}$ is time consuming, difficult to perform and require fasting and is not practical for large-scale projects for young, sick children and is available in just some centers [12].

\subsection{TBW and Stable Isotopes}

The TBW was evaluated in the nineteenth century, by dissection of cadavers. In the twentieth century methods were introduced using substances/marker compounds such as urea, thio-urea, sulfonamides and antipyrine. However, these methods are not exact because the tracer substances are eliminated in individual rates, thus producing an error in the estimation of individual indefinable body water [21].

Conceptually, one element is defined by the number of protons in their core, but the number of neutrons may differ if different stable combinations of nucleus exist. Most of the chemical elements are a mixture of stable isotopes, which do not disintegrate radioactively. Due to the equal number of protons, these occupy the same isotopes (isos) position (topos) in the periodic table of the elements. However, the stable isotopes of an element is different in its physical, chemical and biochemical characteristics, because of their mass differences, causing thermodynamic and kinetic isotope effects [22].

To assess the body composition of an individual, the body water can be used and measured by the ingestion of a dose of labeled water. The measured isotope enrichment is a function of the amount of body water. The body composition is then calculated from the measured water, based on the coefficient of hydration of the FFM. This method consists in determining the amount of TBW from a known dose of the isotope. Assuming a fixed percentage of body water, and that fat contains no water; it is possible to estimate the FFM. The amount of body fat is the difference between total body mass and FFM [23].

\subsection{TBW and Deuterium}

In addition to being fully interchangeable with water, diffusible in all compartments of body fluids and to achieve a stable equilibrium uniform, the substance used as a marker for the determination of the TBW should not be selectively stored, metabolized or secreted. There should be no toxic signs or physiological effects caused by marker $[16,17]$. 
Among all the isotopes that would be expected to show the greatest differences from the original element, are precisely the hydrogen isotopes. The addition of one or two protons to an atom relatively large is a change insignificant compared to that change experienced by the hydrogen with its nearest isotope-deuterium, because here the extra proton nearly doubles the mass. Indeed, the deuterium is often described as a "new element" [24].

The measurement of TBW through the use of deuterium water was first proposed by von Hevesy and Hofer in 1934 and subsequently applied by Moore 1946 [25], also being developed in the early 1950s. The method, in essence, turns the body into its own recorder metabolic [16]. In the 1930s, large amounts of deuterium had been obtained, and the first studies of its toxicity were performed only a year after its discovery in 1932. Between 1934 and 1939, a total of 216 publications on the biological effects of deuterium appeared [22,26].

When organic substances are synthesized in the presence of heavy water, the atoms of deuterium (D) are incorporated into new molecules in an amount proportional to its concentration in the water body. Since these D atoms are fixed in a stable position, the amount of deuterium incorporated in such organic substances can be measured and, by suitable means, its location in organic molecules can even be determined [16].

However, the volume or space dilution hydrogen, understood as the overall hydrogen switchable [16], is greater than the so-called water space, due to the exchange with the hydrogen of proteins and other constituents of the body. This causes an overestimation of the TBW. The exact error is a debate, but it is generally estimated to be between $1 \%$ and $5 \%$ [25].

As the deuterium molecule $\left(\mathrm{D}_{2} \mathrm{O}\right)$ has a radius of only $0.1 \%$ higher than $\mathrm{H}_{2} \mathrm{O}$, the diffusion of the two types of water occurs essentially at the same rate under the same conditions. Thus, it became apparent that heavy water is readily absorbed from the gastrointestinal tract and passes through a variety of animal membranes, virtually the same rate as does the normal water. The easy passage of heavy water using various animal membranes was first demonstrated by Hevesy and Hofer in 1934 in experiments with goldfish [24].

Lucke and Harvey in 1934 also revealed the discovery that the molecule $\mathrm{D}_{2} \mathrm{O}$ permeates the biological membrane as quickly as water. Edelman, in 1952 showed that 2 hours after application, the concentration of $\mathrm{H}_{2} \mathrm{O}$ in $\mathrm{D}_{2} \mathrm{O}$ reached a plateau of identical values in all tissues of the body [21].

Regarding the equilibrium time, the emergence of $\mathrm{D}_{2} \mathrm{O}$ in blood in the first three hours after oral ingestion establishes graphcally a typical curve, whose level is reached 90 minutes after its ingestion, indicating the stable and homogeneous distribution of $\mathrm{D}_{2} \mathrm{O}$ in water compartment
[21]. Thus, the equilibration time of deuterium oxide with body fluids, both after oral ingestion as subcutaneous injection, is about three hours. The elimination of $\mathrm{D}_{2} \mathrm{O}$ via the urine, occurs over time, in the form of water [27].

The water molecule is about $75 \%$ of body weight, their hydrogen atoms are also easily exchangeable with deuterium in the aqueous phase, and only a fraction of the hydrogen atoms in organic compounds body is interchangeable. From calculations based on these facts, it was observed that hydrogen from water body constitutes at least $95 \%$ of the total weight of exchangeable hydrogen. When the total amount of deuterium injected is divided by the concentration in serum after one hour, the resulting figure should represent a precise estimate of TBW. Urinary excretion of deuterium is negligible in the short period of time involved [17].

All the evidence seems to indicate that, when a living organism ingests $\mathrm{D}_{2} \mathrm{O}$, there is immediate exchange proportional of $\mathrm{D}$ atoms with $\mathrm{H}$ of hydroxyl amines, while a very slow connection of D starting with carbons C [24]. Therefore, besides the exchange with water to form deuterium $\mathrm{D}_{2} \mathrm{O}, \mathrm{D}$ atoms are also exchanges with $\mathrm{H}$ atoms interchangeable of organic molecules.

Due to the aforementioned changes, which occur rapidly, deuterium injected will be diluted to a volume greater than if were present only in an environment containing water body, which results in an deuterium concentration equilibrium lower than would be observed in the same volume water in vitro [16].

After $\mathrm{D}_{2} \mathrm{O}$ be present in the body, serum samples may be obtained after a short mixing period and balance. The concentration of $\mathrm{D}_{2} \mathrm{O}$ is compared with the concentration of $\mathrm{D}_{2} \mathrm{O}$ injected. By using the basic equation based on the dilution (which relates volume and concentration of the trace before and after the dose) the amount of water in which was mixed $\mathrm{D}_{2} \mathrm{O}$ is calculated [17]. During the equilibration period, the heavy water must reach the blood cross the capillary membrane, mingle with intracellular and extracellular water, establish trade with free groups $\mathrm{H}$ and reach equilibrium with the water stocks, such as cerebrospinal fluid and intestinal contents [16].

In the opinion of Henry Barbour, deuterium provides a "generally unfavorable environment" for biological activity, and exerts "differential effects on the rate of biochemical reactions" [24]. Some of the changes transmitted to the water by deuterium, when hydrogen is replaced to form deuterium oxide, are increases in melting and boiling points, respectively, in $3.82^{\circ} \mathrm{C}$ to $1.42^{\circ} \mathrm{C}$. The solubility of sodium chloride is reduced by $15 \%$, the viscosity is increased by about $25 \%$, the steam pressure is reduced and the specific gravity is increased to 1.1074 . Some of these properties would certainly be expected to lead to changes in living organisms where substantial 
proportions of body water are replaced by heavy water [24].

Thus, the toxicity of $\mathrm{D}_{2} \mathrm{O}$ has been widely investigated. During long-term studies in mice, fertility appears to be impaired if the concentrations of $\mathrm{D}_{2} \mathrm{O}$ exceed a volume fraction of 0.20 , and this effect was completely reversible [28-30]. Significant dips in the growth rate of fibroblasts were found using the volume fractions above 0.20 in vitro [21,31]. Therefore, during the evaluation of shortterm, concentrations of markers $\mathrm{D}_{2} \mathrm{O}$ should not exceed the volume fraction of 0.01 , or $10 \mathrm{~g} / \mathrm{kg}$ [21]. It was concluded that the threshold for clinically relevant side effects in human adults is between $70-140 \mathrm{~g}$ of $100 \% \mathrm{D}_{2} \mathrm{O}$ or about $200-400 \mathrm{mg}$ deuterium $/ \mathrm{kg}$ bodyweight. The dosage used in clinical tracer studies is clearly lower and ranges from 1 - $80 \mathrm{mg}$ deuterium/ $\mathrm{kg}$ bodyweight [22,32]. From $100 \mathrm{~g}$ of $\mathrm{D}_{2} \mathrm{O}$ in humans produces a serum concentration of only $0.2 \%$, an amount used far below the toxic level, and no side effects were observed after administration of $\mathrm{D}_{2} \mathrm{O}$ to normal individuals or patients [16].

\section{4. $\mathrm{TBW}$ and $\mathrm{H}_{2}{ }^{18} \mathrm{O}$}

The ${ }^{18} \mathrm{O}$ has been considered an ideal marker for water, because it is not radioactive and toxic [25]. Furthermore, in comparative studies of Lifson and McClintock in 1955 using ${ }^{2} \mathrm{H}_{2} \mathrm{O}$ (or $\mathrm{D}_{2} \mathrm{O}$ ) and $\mathrm{H}_{2}{ }^{18} \mathrm{O}$ in mice, $\mathrm{H}_{2}{ }^{18} \mathrm{O}$ was shown to be a more accurate marker for the body water. This probably results from less exchange with nonaqueous constituents of the body [25].

In the $1980 \mathrm{~s}$, it was found that the space $\mathrm{H}_{2}{ }^{18} \mathrm{O}$ dilution averaged $3.0 \%(\mathrm{SD}=0.4)$ smaller than the space ${ }^{2} \mathrm{H}_{2} \mathrm{O}$ dilution, on the basis of subsequent exchanges with non-aqueous hydrogen. For this reason, dilution with $\mathrm{H}_{2}{ }^{18} \mathrm{O}$ should be a more accurate measure of total body water than ${ }^{2} \mathrm{H}_{2} \mathrm{O}$ [25].

The time to equilibrate $\mathrm{H}_{2}{ }^{18} \mathrm{O}$ within the body, as evidenced by the threshold values of the respiration and serum, was 1 to 2 hours in normal subjects and from 2 to 3 hours in obese. This equilibration time is similar to that previously observed for $\mathrm{D}_{2} \mathrm{O}[25,33]$.

In previously reported studies in small animals, rates of distribution of $\mathrm{H}_{2}{ }^{18} \mathrm{O}$ and ${ }^{2} \mathrm{H}_{2} \mathrm{O}$ had been very similar [25,34].

The ${ }^{18} \mathrm{O}$ is eliminated from the body as carbon dioxide and water. The difference in the rates of elimination of isotopes, after adjustment to isotopic fractionation, is a measure of the rate of $\mathrm{CO}_{2}$ production, which can be used to calculate the Total Energy Expenditure [27].

\subsection{Stable Isotopes-Preparation and Collection}

The preparation of dosages and collection of material that will be used is critical for the analysis. Some infor- mation is fundamental when it comes to research with stable isotopes, such as security of supply and source of the marker, chemical purity guaranteed and confirmed independently. For intravenous use, solutions must be sterile, pyrogen-free, and should possess stability marking and chemical stability [22].

Analytical errors are determined by the factors that the investigator can manipulate, such as the delivered dose, the duration of the period metabolic, processing of samples and measurement errors during mass spectrometry. Furthermore, the amount of water dose administered to the individual is one of factors which may alter the accuracy of the method. The administration of the very little isotope also can result in a low enrichment of the body fluid at the end of the study, which leads to larger errors in measurement. To ensure delivery of a sufficient dose of isotope, it is typically calculated for each subject, based on individual body weight [27,35-39].

Several studies are recognized and use methodologies referenced in relation to the process of dispensing and collecting, verifying several protocols used as Table 1. Are observed uses of $99.8 \%$ and $99.9 \%$ excess atomic ${ }^{2} \mathrm{H}_{2} \mathrm{O}[12,40]$. By oral administration, dosages are prepared and distributed into individual vials to be ingested by each child. Are also prepared bottles with the individual identification number for collection and storage of saliva samples [23].

Using saliva to measure the TBW, it was determined that its production rate was sufficient to prevent a significant delay in the isotopic distribution compared to plasma [41].

After an overnight fasting, and after emptying the bladder, samples of saliva baseline (pre-dose) are collected $[40,42]$, should be avoided consumption of foods and liquid an hour before and three hours after this moment [21]. The next step is to collect a saliva sample before ingestion of a standard dose of deuterium. Are reported amounts ranging from $2 \mathrm{ml}$ and $3 \mathrm{ml}[12,23]$. The post-dose samples of saliva may be collected protocols ranging between $1 \mathrm{~h}$ and $8 \mathrm{~h}$ after ingestion of the dose, according to Table 1. Intervals greater than 3 hours are recommended especially in patients with edema, ascites, pleural effusions, or shock [41].

Some recommendations should also be considered when it comes to preparing and collection, as the permanence of the subjects in the supine position. Another important fact for the accurate detection of concentrations of $\mathrm{D}_{2} \mathrm{O}$ in the urine or saliva sample is distillation prior to analysis, so as to eliminate all background effects. The absorbance of non-distilled urine is not constant, giving falsely elevated and dispersed. The urine distilled, however, reveals the normal concentration accurately. The absorption of saliva distilled is identical to the absorbance of demineralized water [21]. 
Table 1. Studies on body composition assessment with isotope dilution, considering the dose supplied, samples, materials collected, the collection intervals and authors.

\begin{tabular}{ccccc}
\hline Dose offered & Sample evaluated & Materials collected & Collection intervals & Authors \\
\hline $30-40 \mathrm{~g}$ & 9 young people aged $14.2( \pm 2.1)$ & Saliva/blood & $3 \mathrm{~h}, 4 \mathrm{~h}, 6 \mathrm{~h}$ & SCHOELLER et al. (1982) \\
$30 \mathrm{~g} / \mathrm{Kg}$ & 5 individuals & Saliva & $4 \mathrm{~h}, 5 \mathrm{~h}, 6 \mathrm{~h}$ & JENNINGS et al. (1995) \\
$0.4 \mathrm{ml} / \mathrm{Kg}$ & 146 young people aged $5-18$ years & Blood & $9 \mathrm{~h}$ & WABITSCH et al. (1996) \\
$0.4 \mathrm{~g} / \mathrm{Kg}$ & 41 children aged $6-12$ years & Saliva & $5 \mathrm{~h}, 6 \mathrm{~h}$ & WELLS et al. (1999) \\
$1 \mathrm{~g} \mathrm{per} \mathrm{child}$ & 213 children aged $6-18$ months & Saliva & $3 \mathrm{~h}, 4 \mathrm{~h}$ & GIGANTE et al. (2002) \\
$0.1 \mathrm{mg} / \mathrm{Kg}$ & 411 young people aged $6-18$ years & Saliva & $2 \mathrm{~h}$ & SOPHER et al. (2004) \\
$2.5 \mathrm{~g} / \mathrm{Kg}$ & 95 children aged $6-12$ years & Urine & $3 \mathrm{~h}, 4 \mathrm{~h}$ & ROBOTHAM et al. (2006) \\
$0.15 \mathrm{mg} / \mathrm{Kg}$ & 17 children & Saliva & $1 \mathrm{~h}, 2 \mathrm{~h}, 3 \mathrm{~h}, 4 \mathrm{~h}$ to $8 \mathrm{~h}$ & BARBOSA-CORTÉS et al. (2007) \\
\hline
\end{tabular}

Care must be taken to ensure that the cotton rolls saliva collectors are free of absorbed water. Failure to drycotton can result in a relative error between $1 \%$ and $2 \%$ to determine TBW because of the dilution of $1 \mathrm{~g}$ to $3 \mathrm{~g}$ of water absorbed by saliva. Moreover, even though the $\mathrm{D}_{2} \mathrm{O}$ method ideal for applications in field studies involving either children or infants, attention should be paid also to saliva contamination of the milk, being a potential problem in infants [41].

Periods longer than 3 - $4 \mathrm{~h}$ for urine collection are necessary to ensure that the isotopic equilibrium is reached, and the use of serum is less than ideal for pediatric studies because it requires a large volume, besides constituting a set invasive [25].

After collection, there are reports that the samples should be stored at a temperature of approximately $-15^{\circ} \mathrm{C}$ or $-30^{\circ} \mathrm{C}$ to blood collected and $-70^{\circ} \mathrm{C}$ for saliva, and sent for analysis $[16,40,42]$. The deuterium dilution space is estimated using the plateau method and converted into TBW dividing by 1.04 , or more specifically $1.044[19,40$, 43-45].

\subsection{Stable Isotopes and Laboratory Analyzes}

The doubly labeled water method is still very sensitive to the precision of isotopic analyzes. The number of participants in a given study by itself does not guarantee that the method is or is not sufficiently developed to correlation analysis, because its accuracy also varies between laboratories [37,38,46,47].

The measurement of TBW by dilution with deuterium oxide in humans is a well-established method and accurate. Typically, concentrations of $\mathrm{D}_{2} \mathrm{O}$ can be measured from serum, saliva or urine by infrared spectroscopy, vacuum distillation and infrared absorbance, nuclear magnetic resonance (NMR), gas chromatography and/or mass spectrometry $[15,21,22,31]$. Using appropriate dosages in humans, enrichments of deuterium are low and must actually be measured by isotope ratio mass spectrometry ${ }^{2} \mathrm{H} / \mathrm{H}$ [25].

\section{RESULTS AND DISCUSSION}

The lean body mass (LBM) is composed of water, minerals and about $73 \%$ protein. These data form the basis of most protocols for assessment of body composition, being difficult to measure by simple methods [15].

Another important aspect to consider is that it should be possible to determine changes in the FFM during weight reduction by appropriate programs for this purpose, during which it remains stable, and should preferably be reduced FM [42].

Although there are some considerations about the gold standard for body composition analysis, none of the techniques in vivo can be considered to meet the highest standards of accuracy. In vivo techniques do not quantify body composition directly, but to predict, from measurements of body properties [14].

Apart from the use of TBW for determining the nutritional studies on body composition, it may have clinical applications [25]. Some examples are shown in Table 2. In the case of the group of HIV-infected patients at risk of malnutrition, the assessment of body composition by isotope dilution with deuterium oxide has been shown to be superior when compared to other methods of evaluation [48], including in relation to the bioimpedance-BIA, which underestimated overhydration tissue in adult patients with chronic renal failure [49].

\section{CONCLUSIONS}

There is a growing consensus that assess body composition in children and adults will raise the profile of health in the countries, an important step to guide interventions in healthcare. The isotope dilution with deuterium oxide is an interesting method because it has low running cost, accuracy, practicality, can be applied under field conditions, poses no risk or discomfort, requires minimal co- 
Table 2. Clinical applications of total body water evaluated by isotope dilution with deuterium oxide and associated aspects.

\begin{tabular}{|c|c|}
\hline Clinical situation & Aspects associated \\
\hline HIV-infected patients at risk of malnutrition & Has shown to be superior when compared to other methods of evaluation [48] \\
\hline Adults with chronic renal failure & Fluid retention tissue is associated with co-morbidities in these patients [49] \\
\hline Patients undergoing chronic peritoneal dialysis & There is evidence for abnormal distribution of body water [50] \\
\hline Patients undergoing hemodialysis & $\begin{array}{l}\text { The equilibrium kinetics of deuterium in this group have similar behavior to that observed in } \\
\text { healthy individuals [51] }\end{array}$ \\
\hline Patients with liver cirrhosis & Malnutrition, overweight and edema along the course of the disease [52] \\
\hline Children with rheumatoid arthritis & $\begin{array}{l}\text { The chronic inflammation and subclinical malnutrition may be responsible for changes in the } \\
\text { distribution of total body water observed [53] }\end{array}$ \\
\hline Breastfeeding infants exclusively or predominantly & $\begin{array}{l}\text { Potential identification, in addition to the intake of milk, as well as the water source, where } \\
\text { breast-milk or other liquids consumed [54] }\end{array}$ \\
\hline
\end{tabular}

operation from the evaluated, proving to be particularly useful in children and infants, due to the low need for membership. Maybe a useful clinical tool for individuals with normal hydration provides quick results and is safe at recommended doses.

The current references of body composition are based on body mass index assessed in healthy children, but their individual interpretation should be made with caution. The use of stable isotopes, such as deuterium oxide, may constitute a useful tool, safe and more reliable for the determination of body composition. Thus, it would be extremely important to become familiar with this method, which can identify more reliably the overweight and obesity.

\section{ACKNOWLEDGEMENTS}

We would like to thank CAPES and the Graduate Program in Health Sciences of UFSJ for financial support.

\section{REFERENCES}

[1] Friend, A., Craig, L. and Turner, S. (2012) The prevalence of metabolic syndrome in children: A systematic review of the literature. Metabolic Syndrome and Related Disorders, 11, 71-80.

[2] Larsen, L.M., Hertel, N.T., Molgaard, C., Christensen, Rd., Husby, S. and Jarbol, D.E. (2012) Prevalence of overweight and obesity in Danish preschool children over a 10-year period: A study of two birth cohorts in general practice. Acta Paediatrica, 101, 201-207. doi:10.1111/j.1651-2227.2011.02551.x

[3] Gardner, K., Bird, J., Canning, P.M., Frizzell, L.M. and Smith, L.M. (2010) Prevalence of overweight, obesity and underweight among 5-year-old children in Saint Lucia by three methods of classification and a comparison with historical rates. Child: Care, Health and Development, 37, 143-149.

[4] Bishwalata, R., Singh, A.B., Singh, A.J., Devi, L.U. and Singh, R.K. (2010) Overweight and obesity among schoolchildren in Manipur, India. The National Medical
Journal of India, 23, 263-266.

[5] Fuiano, N., Rapa, A., Monzani, A., Pietrobelli, A., Diddi, G., Limosani, A., et al. (2008) Prevalence and risk factors for overweight and obesity in a population of Italian schoolchildren: A longitudinal study. Journal of Endocrinological investigation, 31, 979-984.

[6] Amin, T.T., Al-Sultan, A.I. and Ali, A. (2008) Overweight and obesity and their relation to dietary habits and sociodemographic characteristics among male primary school children in Al-Hassa, Kingdom of Saudi Arabia. European Journal of Nutrition, 47, 310-318. doi:10.1007/s00394-008-0727-6

[7] Otero-González, M. and García-Fragoso, L. (2008) Prevalence of overweight and obesity in a group of children between the ages of 2 to 12 years old in Puerto Rico. Puerto Rico Health Sciences Journal, 27, 159-161.

[8] Padula, G. and Salceda, S.A. (2008) Comparison between references of the overweight and obesity prevalence, through the body mass index, in Argentinean children. Archivos latinoamericanos de Nutrición, 58, 330- 335.

[9] Khang, Y.H. and Park, M.J. (2011) Trends in obesity among Korean children using four different criteria. International Journal of Pediatric Obesity, 6, 206-214. doi:10.3109/17477166.2010.490270

[10] Lazarou, C., Panagiotakos, D.B., Panayiotou, G. and Malatas, A.L. (2007) Overweight and obesity in preadolescent children and their parents in Cyprus: Prevalence and associated socio-demographic factors-The CYKIDS study. Obesity Reviews, 9, 185-193. doi:10.1111/j.1467-789X.2007.00461.X

[11] Abrantes, M.M., Lamounier, J.A. and Colosimo, E.A. (2003) Prevalência de sobrepeso e obesidade nas regiões Nordeste e Sudeste do brasil. Revista da Associação Médica Brasileira, 49, 162-166. doi:10.1590/S0104-42302003000200034

[12] Sopher, A.B., Thornton, J.C., Wang, J., Person, R.N., Heymsfield, S.B. and Horlice, M. (2004) Measurement of percentage of body fat in 411 children and adolescents: A comparison of dual-energy X-ray absorptiometry with a four-compartment model. Pediatrics, 113, 1285-1290. doi:10.1542/peds.113.5.1285

[13] Robothan, D.R., Schoeller, D.A., Mercado, A.B., Mirch, 
M.C., Theim, K.R., Reynolds, J.C., et al. (2006) Estimates of body fat in children by hologic QDR-2000 and QDR 4500A dual-energy X-ray absorptiometers compared with deuterium dilution. Journal of Pediatric Gastroenterology and Nutrition, 42, 331-335. doi:10.1097/01.mpg.0000189373.31697.15

[14] Wells, J.C.K. and Fewtrell, M. S. (2006) Measuring body composition. Archive of Diseases of Childhood, 91, 612617. doi:10.1136/adc.2005.085522

[15] IAEA. (1996) Targeting malnutrition: Isotopic tools for evaluating nutrition worldwide. International Atomic Energy Agency, Viena.

http://www.iaea.org/Publications/Booklets/Malnutrition/s even.html

[16] Schloerb, P.R., Friis-Hansen, B.J., Edelman, I.S., Solomon, A.K. and Moore, F.D. (1950) The Measurement of total Body water in the human subject by deuterium oxide diluition: With a consideration of the dynamics of deuterium distribution. The Journal of Clinical Investigation, 20, 1296-1310. doi:10.1172/JCI102366

[17] Moore, F.D. (1946) Determination of total body water and solids with isotopes. Science, 104, 157-160. doi:10.1126/science.104.2694.157

[18] Jennings, G., Bluck, L., Wright, A. and Eilia, M. (1999) The use of infrared spectrophotometry for measuring body water spaces. Clinical Chemistry, 45, 1077-1081.

[19] Wells, J.C., Fuller, N.J., Dewit, O., Fewtrell, M.S., Elia, M. and Cole, T.J. (1999) Four-component model of body composition in children: Density and hydration of fat free mass and comparison with simpler models. American Journal of Clinical Nutrition, 69, 904-912.

[20] Fuller, N.J., Jebb, S.A., Laskey, M.A., Coward, W.A. and Elia, M. (1992) Four component model for the assessment of body composition in humans: Comparison with alternative methods and evaluation of the density and hydration of fat-free mass. Clinical Science, 82, 687-693.

[21] Fusch, C. and Moeller, H. (1988) Measurement of D2O concentrations at tracer levels in small samples obtained from paediatric patients. Journal of clinical chemistry and clinical biochemistry, 26, 715-721.

[22] Koletzko, B., Demmelmaira, H., Hartlb, W., Kindermann, A., Koletzko, S., Sauerwald, T., et al. (1998) The use of stable isotope techniques for nutritional and metabolic research in paediatrics. Early Human Development, 53, S77-S97. doi:10.1016/S0378-3782(98)00067-X

[23] Gigante, D.P., Santos, I.S., Coitinho, D.C., Valle, N.C.J., Haisma, H. and Valente, G.C.M. (2002) Avaliação do impacto do Programa Nacional do Leite em Alagoas, através de métodos isotópicos: Aspectos metodológicos e resultados preliminares. Revista Brasileira de Epidemiologia, 5, 63-70.

[24] Barbour, H.G. (1937) The basis of the Pharmacological action of heavy water in mammals. Yale Journal of Biology and Medicine, 9, 551-565.

[25] Schoeller, D.A., Van Santen, E., Peterson, D.W., Dietz, W., Jaspan, J. and Klein, P.D. (1980) Total body water measurement in humans with 180 and ${ }^{2} \mathrm{H}$ labeled water. The American Journal of Clinical Nutrition, 33, 26862693.
[26] Klein, P.D. and Klein, E.R. (1986) Stable isotopes: Origins and safety. The Journal of Clinical pharmacology, 26, 378-382. doi:10.1002/j.1552-4604.1986.tb03544.x

[27] Trabulsi, J., Troiano, R.P., Subar, A.F., Sharbaugh, C., Kipnis, V., Schattzkin, A., et al. (2003) Precision of the doubly labeled water method in a large-scale application: Evaluation of a streamlined-dosing protocol in the observing protein and energy nutrition (OPEN) study. European Journal of Clinical Nutrition, 57, 1370-1377. doi:10.1038/sj.ejen.1601698

[28] Amarose, A.P. and Czajka, D.M. (1962) Cytopathic effects of deuterium oxide on the male gonads of the mouse and dog. Experimental Cell Research, 26, 43-61. doi:10.1016/0014-4827(62)90201-X

[29] Hughes, A.M., Bennet, E.L. and Calvin, M. (1959) Production of sterility in mice by deuterium oxide. Proceedings of the National Academy of sciences of the United States of America, 45, 581-586. doi:10.1073/pnas.45.4.581

[30] Oakberg, E.F. and Hughes, A.M. (1968) Deuterium oxide effect on spermatogenesis in the mouse. Experimental Cell Research, 50, 306-314. doi:10.1016/0014-4827(68)90449-7

[31] Murphy, J., Desaive, C., Giaretti, W., Kendall, F. and Nicoline, C. (1977) Experimental results on mammalian cells growing in vitro in deuterated medium for neutronscattering studies. Journal of Cell Science, 25, 87- 94.

[32] Jones, P.J. and Leatherdale, S.T. (1991) Stable isotopes in clinical research: Safety reaffirmed. Clinical Science, 80, 277-280.

[33] Culebras, J.M. and Moore, F.D. (1977) Total body water and the exchangeable hydrogen. Theoretical calculation of nonaqueous exchangeable hydrogen in man. American Journal of Physiology, 232, R54-R59.

[34] Anbar, M. and Lewitus, Z. (1958) Rate of body-water distribution studied with triple labelled water. Nature, 181, 344. doi:10.1038/181344a0

[35] Schoeller, D.A. (1983) Energy expenditure from doubly labeled water: some fundamental considerations in humans. The American Journal of Clinical Nutrition, 38, 999-1005.

[36] Schoeller, D.A., Taylor, P. and Shay, K. (1995) Analytical requirements for the doubly labeled water method. Obesity Research, 3, 14-20.

[37] Roberts, S.B., Dietz, W., Sharp, T., Dallal, G.E and Hill, J.O. (1995) Mulitple laboratory comparison of the doubly labeled water technique. Obesity Research, 3, 3-13.

[38] Ritz, P., Johnson, P.G. and Coward, W.A. (1994) Measurements of $2 \mathrm{H}$ and $18 \mathrm{O}$ in body water: Analytical considerations and physiological implications. British Journal of Nutrition, 72, 3-12. doi:10.1079/BJN19940004

[39] Barbosa-Cortéz, L., Tapia-Rojas, M., López-Aguilar, E., Mejía-Aranguré, J.M. and Rivera-Márquez, H. (2007) Body composition by dilution of deuterium oxide in Mexican children with lymphoma and solid tumors. Nutrition, 23, 739-744. doi:10.1016/j.nut.2007.07.001

[40] Schoeller, D.A., Dietz, W., Van Santen, E. and Klein, D. (1982) Validation of saliva sampling for total body water 
determination by $\mathrm{H}_{2}{ }^{18} \mathrm{O}$ dilution. The American Journal of Clinical Nutrition, 35, 591-594.

[41] Wabitsch, M., Braun, U., Heinze, E., Muche, R., Mayer, H., Teller, W., et al. (1996) Body composition in 5-18year-old obese children and adolescents before and after weight reduction as assessed by deuterium dilution and bioelectrical impedance analysis. The American Journal of Clinical Nutrition, 64, 1-6.

[42] Schoeller, D.A., Kushner, R.F. and Taylor, P. (1985) Measurement of total body water: Isotope dilution techniques. In: Roche, A.F., Ed., Body Composition Assessments in Youth and Adult Sixth Ross Conference on Medical Research, Ross Laboratories, Columbus, 124-129.

[43] Racette, S.B., Schoeller, D.A., Luke, A.H., Shay, K., Hnilicka, J. and Kushner, R.F. (1994) Relative dilution spaces of $2 \mathrm{H}$-and 18O-labeled water in humans. American Journal of Physiology, 267, E585-E590.

[44] Hewitt, M.J., Going, S.B., Williams, D.P. and Lohman, T.G. (1993) Hydration of the fat-free body mass in children and adults: Implications for body composition assessment. American Journal of Physiology, 265, E88-E95.

[45] Speakman, J.R. (1995) Estimation of the precision in DLW studies using the two-point methodology. Obesity Research, 3, S31-S40.

[46] Schoeller, D.A. (1999) Recent Advances from Application of Doubly Labeled Water to Measurement of Human Energy Expenditure. The Journal of Nutrition, 129, 17651768.

[47] Diouf, A., Gartner, A., Dossou, N.I., Sanon, D.A., Bluck, L., Wright, A., et al. (2009) Validity of impedance-based predictions of total body water as measured by $2 \mathrm{H}$ dilution in African HIV/AIDS outpatients. The British Journal of Nutrition, 101, 1369-1377. doi: $10.1017 / \mathrm{S} 0007114508067640$
[48] Chan, C., Mclntyre, C., Smith, D., Spanel, P. and Davies, S.J. (2009) Combining near-subject absolute and relative measures of longitudinal hydration in hemodialysis. Clinical Journal of the American Society of Nephrology, 4, 1791-1798. doi:10.2215/CJN.02510409

[49] Arkouche, W., Fouque, D., Pachiaudi, C., Normand, S., Laville, M., Delawari, E., et al. (1997) Total body water and body composition in chronic peritoneal dialysis patients. Journal of the American Society of Nephrology, 8 , 1906-1914.

[50] Chan, C., Smith, D., Spanel, P., McIntyre, C.W. and Davies, S.J. (2008) A non-invasive, on-line deuterium dilution technique for the measurement of total body water in haemodialysis patients. Nephrology, Dialysis, Tranplantation, 23, 2064-2070. doi:10.1093/ndt/gfn045

[51] Strauss, B.J., Gibson, P.R., Stroud, D.B., Borovnicar, D.J., Xiong, D.W. and Keogh, J. (2000) Total body dual X-ray absorptiometry is a good measure of both fat mass and fat-free mass in liver cirrhosis compared to "gold-standard" techniques. Melbourne Liver Group. Annals of the New York Academy of Sciences, 904, 55-62. doi:10.1111/j.1749-6632.2000.tb06421.x

[52] Bedogni, G., Polito, C., Severi, S., Strano, C.G., Manzieri, A.M., Alessio, M., et al. (1996) Altered body water distribution in subjects with juvenile rheumatoid arthritis and its effects on the measurement of water compartments from bioelectric impedance. European Journal of Clinical Nutrition, 50, 335-339.

[53] Medoua, G.N., Sajo Nana, E.C., Ndzana, A.C., Makamto, C.S., Etame, L.S., Rikong, H.A., et al. (2012) Breastfeeding practices of Cameroonian mothers determined by dietary recall since birth and the dose-to-the-mother deuterium-oxide turnover technique. Meternal and Child $\mathrm{Nu}$ trition, 8, 330-339. 